\title{
Procedimientos olvidados en ginecoobstetricia
}

\author{
Emilio Alberto Restrepo Baena*
}

\begin{abstract}
RESUMEN: Se describen varios procedimientos diagnósticos y terapéuticos que fueron usados en la evolución de la ginecoobstetricia y que por lo agresivos, o por la iatrogenia que causaban fueron descartados de la práctica moderna.

PALABRAS CLAVES: Procedimientos, historia, iatrogenia.

SUMMARY: We describe several diagnosis and therapeutic procedures used in the past gineco obstetrical history and forgotten today because was very aggressive and iatrogenic.
\end{abstract}

KEY WORDS: Procedures, history, iatrogenic.

\section{Introducción}

La ginecoobstetricia a través de la evolución siempre ha tenido como fin primordial la prevención y curación de las enfermedades propias de la mujer, así como la consecución de un embarazo llevado a un feliz término.

En el logro de este objetivo ha diseñado todo un arsenal diagnóstico y terapéutico, de una riqueza semiológica y de recursos, que ponen a prueba la agudeza clínica y la habilidad terapéutica del médico. En muchos casos el resultado es afortunado, pero en otros, la gravedad del cuadro se ve empeorada por la agresividad de un procedimiento de profundas repercusiones sobre la salud de la paciente. La Historia ha sido testigo de tales métodos y ella misma se ha encargado de revisarlos y confinarlos al ostracismo ante la iatrogenia que generan. En otras ocasiones, si bien el método no es tan radical, no deja de ser interesante el enunciarlo pues a nuestro criterio moderno nos puede parecer llamativo o acaso un poco folclórico, cuando no empírico.

Elobjetivo de esta revisión es recopilar y describir algunos de estos procedimientos para que el ginecoobstetra de nuestros días tenga una visión general de ellos.

\section{Cesárea vaginal (histeretomía vaginal)}

Cuando la cesárea abdominal implicaba una importante morbimortalidad materna, se llegó a practicar esta técnica. Se separa la vejiga de la cara anterior del cuello y del segmento uterino anterior. Se incide longitudinalmente, se aplican forceps o la maniobra de versión-extracción, se repara todo por planos. Esto se conocía como parto forzado(accouchement forcé). Produjo muchas muertes, motivo por el cual fue abandonado (1).

\section{Histerostomatomía (incisiones de Duhrssen)}

Cuando era necesario la terminación de un parto antes que el cuello estuviera completamente dilatado, se recurría a

* Residente de Ginecoobstetricia Universidad de Antioquia hacer incisiones radiales del cervix, a los dos, seis y diez horas del reloj, para después hacer una extracción con forceps o en podálica según la presentación. Esto implicaba en ocasiones, forceps medios o altos, severas hemorragias, rupturas uterinas, desgarros vaginales o vesicales, estenosis cervical, etc. Estas incisiones fueron abandonadas (1-3).

\section{Sinfisiotomía y pubiotomía}

La primera busca seccionar la articulación o sínfisis del pubis con una sierra o un bisturí; pretende aumentar la capacidad de una pelvis estrecha. En la segunda se corta el hueso púbico unos centímetros a la derecha o izquierda de la sínfisis.

Ambos procedimientos producen repercusiones sobre la locomoción, lesiones vesicales, hemorragias, dolor crónico, osteomielitis, que los hacen inutilizables hoy en día $(1-2,13)$.

\section{Craneotomía}

Busca reducir el volumen de la cabeza fetal para facilitar la extracción de un feto muerto retenido o hidrocefálico. Consiste en la perforación del cráneo fetal con la expulsión de la masa encefálica, luego de lo cual hay contracción craneal que hace fácil la extracción con el instrumento de tracción. Para este fin se utilizaron varios instrumentos, entre ellos el basiotricio de Tarnier, que servía para perforar, fracturar, comprimir y traccionar, también el perforador de Blot, el craneoclasto de Braun, el deculador de Ribemont y la tijera de Dihois Pinard $(1-2,4)$.

\section{Embriotomía}

Buscaba extraer vísceras fetales por una abertura torácica o abdominal (evisceración) o separar la cabeza del tronco (decapitación). Se utilizaba en monstruos o fetos cuya cavidad abdominal o torácica estaban aumentadas por tumor o megalias. La técnica consistía en incidir el abdomen y con los dedos del cirujano se desgarraban las vísceras. La decapitación se hace con un cuchillo en forma de hoz. Con una sierra de alambre se incidía "en banda presidencial", para la 
embriotomía. Esto se hacía cuando había una transversa descuidada con hombro encajado en el canal pélvico y segmento uterino inferior muy distendido $(1-2,4)$.

Estos dos últimos procedimientos, muy impresionantes por cierto, han sido casi abandonados por la obstetricia moderna. Dos variantes más "benévolas" son la punción con aguja de la cabeza hidrocéfala o la cleidotomía en retención de hombros.

\section{Cirugía para la frigidez}

En 1956, Halban, citado por Montobio (5), propone una cirugía que consiste en bajar el clítoris por sección de su ligamento suspensorio a través de una incisión en $\mathrm{V}$ de vértice inferior en pleno monte de Venus. Disecado este colgajo, aparece el ligamento suspensorio que se secciona y al reunir los bordes cruentos, resulta una sutura en $\mathrm{Y}$, con abajamiento del glande.

Como tratamiento menos agresivo propone testosterona por vía muscular, a dosis de 75 a $100 \mathrm{mg}$ repartidas en la segunda mitad del ciclo por 3 a 4 meses.

\section{Cirugía para el vaginismo}

Cattaneo describió una técnica para las mujeres que han desarrollado un vaginismo severo, refractario a toda sicoterapia y que no muestra patología orgánica asociada. Proponía elevar un colgajo de mucosa vaginal para descubrir los músculos bulbocavernoso, transverso y elevador del ano, y luego seccionarlos, volviendo a recubrir lo cruento con el colgajo de mucosa. No habla de las implicaciones de la cirugía sobre el piso pélvico (5).

\section{Técnica para aborto del segundo semestre}

Se usa depósito intra o extra ovular de diferentes sustancias (rivanosulfamida, jabones) a través del conducto cervical, por vía transabdominal, o por fondos de saco anterior o posterior. En la experiencia de Rovinsky (3) la instilación de una solución de formaldehido al $40 \%$ da buenos resultados.

\section{Tacto vaginal intrauterino}

En paciente con prolapso que tenga metrorragias se puede hacer una dilatación con bujías de Hegar hasta llegar a la número 14. La dilatación dura el breve momento que la musculatura uterina tarda en responder con gran energía (5).

\section{Douglascopia (celioscopia vaginal)}

Se hace con un cistoscopio. Se usaba para "sorprender los movimientos de las trompas y la dehiscencia folicular"; además para estudios de esterilidad. Describen "pequeños accidentes" como la perforación del recto, que cura espontáneamente en tres días con opiáceos y reposo. Además, hemorragias y salida de epiplón (5).

\section{Psicoterapia ginecológica}

Busca tratar enfermedades ginecológicas con transfondo neurósico. Se propone para la Amenorrea síquica, menorragias por complejo de repulsión conyugal (?), congestión pélvica con varicocele, flujo rebelde y elongación edematosa del cuello, involución precoz genital, furor uterino, frigidez, dismenorrea esencial, prurito idiopático, esterilidad, algias pélvicas, etc. Se utiliza el método de Weir Mitchell o del aislamiento absoluto con reposo y sobrealimentación. En pocos días se reestablece el equilibrio de los valores morales, lo que equivale a curación. El aislamiento no debe durar más de 4 a 6 semanas. La cura se robustece con baños, masajes, endotermia, gimnasia respiratoria, vitamina B1, calcio IV, sedantes suaves, proteinoterapia, prohibición de toda visita, llamada telefónica o carta. Es indispensable la colaboración de la paciente con "obediencia monástica" (5).

\section{Balones intrauterinos (metreurinter) y otros métodos para placenta previa}

Se aplicaban los balones de Champetier o de Zweifel, que se rellenaban con agua esteril luego de introducirlos vacíos en el ứtero al hacer ruptura de membranas. $\mathrm{Al}$ inflarse, producen compresión de la placenta y hemostasia (6).

Otro procedimiento eran las pinzas de Gauss o Willet que son dispositivos en $\mathrm{T}$ con garfios que pinzan la Galea aponeurótica o cuero cabelludo y traccionan el feto rápidamente hacia abajo cuando hay placenta previa sangrante (6).

Botella (6) recomienda a los médicos rurales, ante el diagnóstico de placenta previa sangrante, intentar una versión bidigital combinada o maniobra de Braxton-Hicks, introduciendo dos dedos por el cuello sin importar su dilatación, coger un pie del feto y completar la versión. Luego se coloca un peso en el pie fetal para que ejerza una acción lenta pero continua sobre el cuello para que las nalgas compriman la placenta, impidiendo la hemorragia y acelerando el parto.

\section{Manejo de la preeclampsia}

Para la prevención y manejo de las convulsiones en la toxemia, la edición de Williams de 1960 recomienda la utilización de Paraldehido con Aceite de Oliva por vía rectal cada 6 horas, pues lo considera buen hipotensor, eficaz anticonvulsionante, y muy seguro. Lo prefieren al Sulfato de Magnesio y a los barbitúricos (1). Estudios posteriores mostraron como efectos secundarios acidosis, gastritis o proctitis hemorrágica, irritabilidad muscular, azohemia, oliguria, albuminuria, leucocitosis, necrosis grasa del hígado, nefritis, edema pulmonar y farmacodependencia (7).

También advierte que si la preeclampsia se agrava, y es necesario terminar el embarazo por cesárea, la anestesia de elección es la infiltración local (1). Botella (6) usa como de primera elección la asociación de Largactil-Fenergan y Heparina-Vitamina $C$ para evitar el daño epitelial. Consideran que la hipotermia física es un medio efectivo para asociar a los anteriores.

Mucho más agresivo y menos efectivo, han sido los que para el manejo de la Toxemia han utilizado mutilaciones como mastectomía, ooforectomía, trepanación, decapsulación renal, inyección de líquidos por punción lumbar, sangrías, histerectomía, inyección de yoduro potásico intramamario, aplicación de ventosas, etc. (14-15).

\section{Balneoterapia}

Se recomendaron durante mucho tiempo los baños de lodo pues se creía que tenían una acción estrogénica local, favorable en el desarrollo de la función sexual y útil en el tratamiento de amenorreas, esterilidad, frigidez e insuficiencia ovárica (12).

\section{Fototerapia}

Los rayos ultravioleta eran usados en el tratamiento de la TBC exudativa del peritoneo pues se creía que estimulaba la 
síntesis de Vitamina D2 por la irradiación de Ergosterina en los vasos cutáneos. (?) (12).

De la práctica moderna se han ido relegando procedimientos como los FORCEPS ALTOS, por la grave iatrogenia que usualmente desencadenan $(2,11)$.

Aunque todavía se tiene como último recurso en el manejo del cáncer de cervix en estadíos avanzados, la
EXENTERACION pélvica total pierde cada día más terreno dentro del ejercicio ginecológico. Recordemos que este severo procedimiento implica resección amplia, total, de los órganos de la pelvis, con extirpación de la pared vaginal, útero, anexos, vejiga, recto; derivación urinaria e intestinal y linfadenectomía pélvica y paraaórtica. Como se infiere de lo anterior, tiene una alta morbimortalidad con un compromiso importante de la calidad de vida de la paciente (9-11).

\section{BIBLIOGRAFIA}

1. Eastman N. Obstetricia de Williams. 3a. ed. México, Unión Tipográfica Editorial Hispanoamericana, 1960; 1180.

2. Pritchard J., Mac Donald P. Obstetricia de Williams. 2a ed. Barcelona, Salvat Editores, 1969; 969.

3. Rovinski J. Complicaciones médicas, quirúrgicas y ginecológicas del embarazo. 2a ed. México, Ed. Interamericana, 1967; 707-708.

4. Uranga Imaz F. Obstetricia Práctica. 5a ed. Buenos Aires, Ed Intermédica $1979 ; 988$

5. Conill Montobio V. Tratado de Ginecología. 3a ed. Barcelona, Ed. Labor, 1956; 748.

6. Botella J. Patología Obstétrica. Tomo II. 5a ed. Madrid, Ed. Omega, 1961; 705.

7. Goodman L., Gilman A. Bases Farmacológicas de la terapéutica. 5a ed. México, Ed. Interamericana, 1978; 1412.

8. Botero J., Jubiz A., Henao G. Texto integrado de Obstetricia y Ginecología. 4a. ed. Medellín, Ed. Carvajal, 1990; 812.
9. Kistner AW. Tratado de Ginecología. 2a. ed. Barcelona, Ed. Toray S.A. 1960; 168-170.

10. Mattlingly R., Thompson J. Ginecología operatoria de Telinde. 6a. ed. Buenos Aires, Librería El Ateneo Editorial, 1987; 819.

11. De Gruyter. Diccionario Pschyrembel de Ginecología y Obstetricia. Berlín, Walter de Gruyter \& Co. 1988; 295.

12. Botella J. Tratado de Ginecología. Tomo III. Enfermedades del aparato genital femenino. 6a ed. Barcelona, Editorial Científico Médico, 1962; 656.

13. Laín Entralgo P. Historia Universal de la Medicina. Barcelona, Salvat Editores, 1975.

14. Symonds EM. Estados hipertensivos del embarazo. En: Ginecología y Obstetricia, Temas Actuales. México, Ed. Interamericana, 1977; 717.

15. Dieckmann W. The Toxemias of Pregnancy. 2 th ed. St Louis, The C.V. Mosby Company 1952; 507-516. 